\title{
O que é um "bom" artigo científico? Concepções de estudantes do curso de Engenharia Elétrica
}

I Universidade Federal de Campina Grande (UFCG). Campina Grande, Paraíba, Brasil. E-mail: <professoraelizabethsilva@ gmail.com>; <https://orcid. org/0000-0002-1355-493X >.

II Doutora em Educação pela Universidade Federal de Minas Gerais (UFMG). Belo Horizonte, Minas Gerais, Brasil.

III Universidade Federal de Campina Grande (UFCG). Campina Grande, Paraíba, Brasil. E-mail: $<$ mariaariane569@gmail. com>; <https://orcid. org/0000-0002-5083-4973>.

IV Acadêmica em Letras Língua Portuguesa pela Universidade Federal de Campina Grande (UFCG). Campina Grande, Paraíba, Brasil.

v Universidade Federal de Campina Grande (UFCG). Campina Grande, Paraíba, Brasil. E-mail: <raquellaurentino98@ gmail.com>; <https://orcid. org/0000-0002-8141-1826>.

vI Acadêmica em Letras Língua Portuguesa pela Universidade Federal de Campina Grande (UFCG). Campina Grande, Paraíba, Brasil.

VII Universidade Federal de Campina Grande (UFCG). Campina Grande, Paraíba, Brasil. E-mail: <jujusidebrito@gmail. com>; <https://orcid. org/0000-0001-5725-0738>.

VIII Acadêmica em Letras Língua Portuguesa pela Universidade Federal de Campina Grande (UFCG). Campina Grande, Paraíba, Brasil.

\author{
Elizabeth Maria da Silva ${ }^{\mathrm{I}, \mathrm{II}}$ \\ Maria Ariane Santos Amaro da Silva ${ }^{\mathrm{III}, \mathrm{IV}}$ \\ Raquel Laurentino Cunhav,vi \\ Júlia Juliêta Silva de Brito ${ }^{\mathrm{VII}, \mathrm{VIII}}$ \\ http://dx.doi.org/10.24109/2176-6681.rbep.101i259.3911

\section{Resumo}

Este estudo tem o objetivo de identificar concepções de artigo científico utilizadas por estudantes da área de Engenharia Elétrica de uma universidade federal brasileira. Embora valiosas contribuições já tenham sido dadas em materiais didáticos voltados para a didatização desse gênero, nota-se a escassez de pesquisas sobre os propósitos comunicativos e os significados sociais específicos de artigos científicos produzidos e publicados nas diferentes áreas do conhecimento. Por isso, o foco deste estudo são as perspectivas dos próprios integrantes de uma dessas áreas: exploram-se aqui entrevistas semiestruturadas realizadas com estudantes de Engenharia Elétrica, sob uma abordagem qualitativa e uma perspectiva experiencial, tomando como base a metodologia de análise de conteúdo. Fundamentada nos discursos sobre escrita, a análise dos dados conclui que as percepções desses estudantes sobre o que se espera de um "bom" artigo científico apontam duas dimensões: o artigo como prática social e o artigo como prática sociopolítica. As discussões realizadas neste trabalho podem contribuir para ampliar o debate sobre a produção de gêneros acadêmicos.

Palavras-chave: artigo científico; concepção de escrita; produção científica. 


\section{Abstract \\ What is a "good" scientific article? Students' from the Electrical Engineering undergraduate course's conceptions}

This paper aims to identify the conceptions of scientific article used by the Electrical Engineering students of a Brazilian federal university. Despite valuable contributions that were made in learning materials related to teaching students how to write this genre of text, there is a lack of research on communicative goals and specific social meanings of scientific articles produced and published in different areas of knowledge. In order to help fill in this blank, this study focuses on examining transcripts of semi-structured interviews with students of one of these areas, electrical engineering, and examining their viewpoints. A qualitative approach was used, as well as an experiential perspective based on a content analysis methodology. The data analysis shows that there are two perceptions these students have about what is expected from a "good" scientific article: the article as a social practice and the article as a sociopolitical practice. The results achieved in this work may contribute to broaden the debate on the production of academic genres in different areas of knowledge, based on the conceptions of undergraduate students themselves.

Keywords: conceptions of writing; scientific article; scientific production.

\section{Resumen \\ ¿Qué es un "buen" artículo científico? Concepciones de estudiantes del curso de Ingeniería Eléctrica}

Este estudio tiene como objetivo identificar concepciones de artículo científico utilizadas por estudiantes del área de Ingeniería Eléctrica de una universidad federal brasileña. Aunque ya se han realizado valiosas contribuciones en materiales didácticos destinados a enseñar este género, existe una falta de investigación sobre los propósitos comunicativos y los significados sociales específicos de los artículos científicos producidos y publicados en diferentes áreas del conocimiento. Por lo tanto, el enfoque de este estudio son las perspectivas de los miembros de una de estas áreas. En el caso de este trabajo, se exploran entrevistas semiestructuradas con estudiantes de Ingeniería Eléctrica, utilizando un enfoque cualitativo y una perspectiva experimental, basada en la metodología de análisis de contenido. Basado en los discursos sobre la escritura, el análisis de los datos muestra que las percepciones de estos estudiantes sobre lo que se espera de un "buen" artículo científico apuntan a dos concepciones: el artículo como práctica social y el artículo como práctica sociopolítica. Las discusiones 
realizadas en este trabajo pueden contribuir para ampliar el debate sobre la producción de géneros académicos.

Palabras clave: artículo científico; concepción de escritura; producción científica.

\section{Introdução}

Nos últimos anos, com a desconstrução da crença de que se aprende a escrever de uma vez por todas (Carroll, 2002) e da consequente compreensão de que a escrita é uma prática social e situada (Street, 2010a), pesquisadores têm se interessado em estudar as especificidades da escrita exigida em diferentes contextos - acadêmicos, profissionais, públicos, midiáticos (Bawarshi; Reiff, 2013). Não só estudar a escrita dentro desses contextos, mas também propor formas de didatizá-la a partir, por exemplo, de abordagens de ensino de gêneros, sejam implícitas (Freedman, 1993), sejam explícitas (Swales, 1990), sejam interativas (Devitt, 2004, 2009).

Nos contextos acadêmicos, têm sido apresentadas propostas de didatização de gêneros como o resumo, a resenha, o relatório de estágio e o artigo científico. A propósito desse último gênero, objeto de investigação desta pesquisa, há alguns materiais didáticos voltados para sua didatização, como, por exemplo, Produção textual na universidade (Motta-Roth; Hendges, 2010) ou Como escrever e ilustrar um artigo científico (Gustavii, 2017). Além disso, há alguns manuais de pesquisa, como Fundamentos de metodologia científica (Marconi; Lakatos, 2003). A produção desses materiais sinaliza a preocupação de ensinar àqueles que ingressam na academia como produzir um dos gêneros mais requisitados nessa esfera, caracterizada por ser um espaço de construção e divulgação de conhecimentos.

Por um lado, há valiosas contribuições para o ensino de artigos científicos, incluindo o interesse em descrever a estrutura desse gênero; por outro, ainda há lacunas quanto ao desenvolvimento de pesquisas focalizando as concepções de graduandos, em especial daqueles que não são da área de linguagem, sobre como se dá a produção desse gênero em sua área (Silva; Castanheira, 2019).

Esse cenário de escassez de pesquisas sobre o artigo científico a partir da perspectiva aqui proposta, levou a investigação das concepções de estudantes do curso de Engenharia Elétrica de uma universidade federal brasileira sobre o que se espera de um artigo científico. Entende-se que ouvir a voz dos partícipes do processo de aprendizagem em relação aos textos demandados no curso do qual fazem parte é crucial, tanto para nortear as escolhas teórico-metodológicas que ancoram o processo de ensino, quanto para se ter uma ideia do(s) modo(s) pelo(s) qual(is) eles enxergam a produção de gêneros em sua área específica. Torna-se ainda mais relevante ouvi-los quando o assunto é a sua visão sobre a produção de 
artigos científicos, gênero bastante requisitado na maioria das comunidades disciplinares. Ademais, conhecer a opinião de alunos de outros cursos, que não o de Letras, no qual teoricamente se ensina a escrever (Oliveira, 2016), permite enriquecer esse debate, até porque a produção de textos não é exclusiva da área da linguagem.

Considerando esse cenário, o questionamento que impulsiona esta pesquisa é: que concepções de artigo científico são mobilizadas por estudantes de Engenharia Elétrica de uma universidade federal brasileira?

Espera-se que as discussões realizadas neste trabalho possam ampliar o debate sobre concepções de gêneros acadêmicos de graduandos vinculados a diferentes áreas do conhecimento, além de permitir a pesquisadores e professores, tanto da área de linguagens quanto de outras áreas, como a de Engenharia Elétrica, (re)conhecer de que forma estudantes desse curso concebem o artigo científico.

Para tanto, o presente texto foi organizado em quatro seções, além dessa introdução. Na primeira, explicitam-se os fundamentos teóricos norteadores da pesquisa - discursos sobre escrita (Ivanic, 2004). Na segunda, apresentam-se os fundamentos metodológicos - abordagem, tipo e corpus da pesquisa, bem como procedimentos analíticos adotados na exploração dos dados. Na terceira, analisam-se os dados coletados, evidenciando as concepções de artigo científico utilizadas pelos graduandos em Engenharia Elétrica. Na quarta e última seção, considerações finais são apresentadas.

\section{Fundamentação teórica}

Nesta seção, apresentam-se concepções de escrita a partir da categorização de discursos sobre escrita proposta por Ivanic (2004).

Segundo Ivanic (2004, p. 2241', tradução nossa), os "discursos de escrita" são "constelações de crenças sobre escrita, crenças sobre aprender a escrever, formas de falar sobre escrita e tipos de abordagens para o ensino e avaliação que estão provavelmente associadas com essas crenças". Partindo dessa definição, a autora propõe seis discursos sobre escrita, quais sejam: habilidades, criatividade, processo, gênero, prática social e sociopolítico. Para cada um desses discursos, a autora apresenta três aspectos: crenças sobre escrita, crenças sobre aprender a escrever e abordagens para o ensino de escrita (Ivanic, 2004). Considerando o objetivo delineado na introdução, este trabalho tomou o primeiro aspecto como foco.

No discurso sobre habilidade, a escrita é concebida como um conjunto de conhecimentos relacionados à relação entre símbolos e sons e aos padrões sintáticos para a construção de um texto (Ivanic, 2004). O foco é atender ao rigor gramatical, sintático, bem como às convenções da língua, como na abordagem de ensino de escrita denominada habilidades de estudo (Lea; Street, 1998). Com essa definição, entende-se que aquele que escreve poderá aplicar esse conjunto de conhecimentos, tidos como neutros e universais, na produção de quaisquer textos, conforme previsto no modelo de letramento autônomo (Street, 1984).
"I am defining 'discourses of writing' as constellations of beliefs about writing, beliefs about learning to write, ways of talking about writing, and the sorts of approaches to teaching and assessment which are likely to be associated with these beliefs". 
No discurso sobre a criatividade, a escrita é concebida como resultado da ação criativa do escritor, do seu engajamento na construção do significado daquilo que produziu (Ivanic, 2004). Para realizar essa atividade criativa que é o ato de escrever, dois elementos são fundamentais, destaca Ivanic (2004): conteúdo e estilo. Esses elementos materializam a voz do escritor e a sua forma de expressar suas experiências enquanto um "eu" que escreve. Nesse sentido, acredita-se que a escrita é um talento, um dom, uma característica inata do indivíduo, de modo que somente aqueles que nascem com esse talento terão maiores possibilidades de obter "sucesso" ao escreverem (Ivanic, 2004).

À semelhança do discurso da criatividade, no discurso da escrita enquanto processo há uma preocupação em se considerar questões cognitivas e individuais daquele que escreve. Entretanto, diferencia-se por focalizar no processo cognitivo, a partir do qual os textos são produzidos pelos indivíduos. Nesse discurso, a escrita é considerada enquanto resultado de processos que ocorrem na mente do escritor. Em consonância com os que defendem os estudiosos da Psicologia Cognitiva, a exemplo de Flower e Hayes (1980), o processo de composição envolvido na escrita é constituído de três elementos centrais: planejamento, tradução e revisão das ideias a serem contempladas em determinado texto. Escrever implica, assim, ter domínio de processos tanto cognitivos - ações que ocorrem na mente do indivíduo quando está compondo um texto - quanto procedimentais, práticos - a execução do ato de escrever (Ivanic, 2004).

Já no discurso sobre gênero, a escrita é considerada um conjunto de tipos de texto compartilhados por um contexto social (Ivanic, 2004). Segundo a autora, escrever é tido como sinônimo de saber dominar as características linguísticas (e estruturais) dos diferentes tipos de texto (os gêneros), a ponto de conseguir reproduzi-los adequadamente, de acordo com os propósitos sociais específicos, em contextos também específicos.

Essa forma de enxergar a escrita está relacionada com a abordagem de ensino de escrita denominada socialização acadêmica (Lea; Street, 1998). Embora o ponto de partida desses pesquisadores tenha sido contextos acadêmicos, essa abordagem, assim como a da habilidade e a dos letramentos acadêmicos, pode perfeitamente ser mobilizada para outros contextos, salientam os autores (Lea; Street, 2006). Nesse sentido, o discurso sobre gênero pode ser associado à abordagem da socialização acadêmica, porque o foco também está no conhecimento e no domínio das características dos gêneros, no caso, daqueles ligados às práticas letradas acadêmicas (Lea; Street, 1998).

Este trabalho adota o de gêneros discursivos proposto por Bakhtin (2003, p. 282): "tipos relativamente estáveis de enunciado" constituídos sócio-historicamente por três dimensões essenciais e indissociáveis construção composicional, conteúdo temático e estilo. A construção composicional diz respeito à estrutura dos textos pertencentes a determinado gênero. Essa estrutura não é fixa, nem estanque, mas flexível e variável, com relativa estabilidade. O conteúdo temático se refere ao que é dito em dado gênero, tanto em relação a questões sociais, ideológicas, 
históricas, culturais e linguísticas, quanto a outros ditos e não ditos, funcionando, nesse segundo caso, como uma resposta a outros enunciados. O estilo, por sua vez, abarca tanto as escolhas individuais do falante/escritor, refletindo sua individualidade, quanto os modos específicos de determinados enunciados (Bakhtin, 2003).

De acordo com Bakhtin (2003), essas três dimensões do gênero são delimitadas com base em parâmetros da situação de produção dos enunciados/textos, de modo que esses parâmetros se configuram como elementos definidores de um gênero. Em outras palavras, não é a forma que define o gênero, mas a situação social de interação em que aparece (Rodrigues, 2005). Nesse sentido, faz-se necessário considerar os elementos constitutivos dessa situação - quem fala/escreve, para quem, com que objetivo, por que, que papéis sociais são assumidos por quem fala/escreve e por aquele a quem se dirige. Todos esses elementos, situados em uma dada esfera de atividade humana, constituem-se com base em relações sociais, históricas e institucionais que os definem.

Retomando os discursos sobre escrita, Ivanic (2004) elenca também o de escrita como prática social. A ênfase é, então, no seu propósito comunicativo, definida pelo contexto social em que se configura (Ivanic, 2004). Segundo a autora, escrever significa produzir um texto para cumprir um objetivo dentro da vida real. Trata-se de uma escrita situada, que faz sentido dentro de um dado contexto social, a partir da delimitação de objetivos sociais que sejam relevantes e significativos para aqueles que escrevem.

O discurso de escrita como prática sociopolítica amplia o conceito de prática social, pois nele a escrita é entendida como uma prática construída sócio e politicamente, trazendo consequências para identidade de quem escreve, bem como estando aberta à contestação e à mudança (Ivanic, 2004). Nessa concepção, entende-se que escrever é ter/demonstrar consciência crítica quanto ao fato de que a linguagem é perpassada por forças sociais e relações de poder e identitárias, coadunando-se, assim, com as proposições teóricas norteadoras da abordagem dos letramentos acadêmicos (Lea; Street, 1998).

Salienta-se, por fim, que esses discursos sobre escrita não se apresentam de modo "puro", isolado ou homogêneo. Tendo em vista que são identificados a partir do que as pessoas fazem e dizem com/sobre a escrita, pode ser que haja, em um mesmo contexto de investigação, formas de agir e falar sobre a escrita que se relacionam a um ou mais discursos.

\section{Metodologia}

A investigação apresentada neste artigo faz parte de uma pesquisa mais ampla, intitulada Ensino de Escrita em Contextos Acadêmicos, aprovada pelo Comitê de Ética, sob o CAAE 03520818.4.0000.5182. Situada no âmbito da Linguística Aplicada (Lopes, 2006), fundamenta-se nos pressupostos norteadores do paradigma interpretativo (Moreira; Caleffe, 
2008), da abordagem qualitativa (Bogdan; Biklen, 1994) e da perspectiva experiencial (Micolli, 2006).

O desenvolvimento dessa pesquisa mais ampla permitiu construir um banco de dados constituído tanto por dados documentais (projetos políticos pedagógicos e fluxogramas de todos os trinta e sete cursos de graduação ofertados pela universidade investigada e quarenta e um planos de curso de disciplinas voltadas para o ensino de escrita acadêmica ministradas nesses cursos), quanto empíricos (depoimentos de graduandos desses cursos sobre suas experiências com a escrita acadêmica, gerados a partir da realização de entrevistas semiestruturadas).

Considerando o objeto de estudo e o objetivo delineados na introdução, selecionaram-se como corpus trechos de falas de estudantes do curso de Engenharia Elétrica, matriculados em períodos letivos distintos, com suas opiniões sobre o que é um "bom" artigo científico no curso do qual fazem parte. Essas entrevistas foram realizadas individualmente, no próprio campus da universidade. Mediante a autorização dos sete entrevistados, por meio da assinatura do termo de consentimento livre e esclarecido, foi possível gravar seus depoimentos. No entanto, para garantir a privacidade, codinomes foram utilizados.

Por fim, quanto aos procedimentos analíticos, adotou-se a técnica de análise de conteúdos (Bardin, 2002) marcada por quatro etapas, a saber: unitarização, categorização, descrição e interpretação dos dados. Inicialmente, os conteúdos dos trechos selecionados das entrevistas foram transformados em unidades de análise, tomando como base as escolhas lexicais feitas pelos entrevistados (etapa da unitarização). Em seguida, esses dados foram agrupados, considerando a parte comum entre eles (etapa da categorização). Para tanto, levou-se em conta os discursos sobre escrita propostos por Ivanic (2004), apresentados na seção anterior. Logo após, os aspectos centrais da fala desses participantes foram descritos, considerando os modos pelos quais eles caracterizam um "bom" artigo científico (etapa da descrição). Por último, esses modos de caracterizações foram interpretados, relacionando-os com os discursos sobre a escrita (Ivanic, 2004) e com outros conceitos pertinentes (etapa da interpretação).

\section{O que é um "bom" artigo científico na área de Engenharia Elétrica?}

Nesta seção, trechos das entrevistas realizadas com os estudantes do curso de Engenharia Elétrica são explorados, visando evidenciar suas concepções do que significa produzir um "bom" artigo científico em sua área. Ao fazê-lo, identificam-se duas concepções de escrita subjacentes: artigo como prática social e artigo como prática sociopolítica. Cada uma dessas categorias é o foco das duas subseções seguintes, respectivamente. 
Ao definirem o que é um "bom" artigo científico na área de Engenharia Elétrica, os participantes da pesquisa destacaram, predominantemente, elementos relacionados aos propósitos comunicativos desse gênero. Essa foi a caracterização feita por Alan:

Um bom artigo acadêmico? É... Acho que não é muito, diferente do que é considerado, em geral, um bom artigo acadêmico. É... Um artigo que... traz uma pesquisa relevante; que... De certa forma, se propõe a... Cumpre o que se propõe a fazer, né? Que atende a seus objetivos, pelo menos tenta, é... Também é um artigo que traz boas referências daquilo que já é consolidado na literatura. Não é muito diferente daquilo que já é comum não (Entrevista, Alan, 2019).

No segmento exposto, Alan caracteriza um "bom" artigo como "um artigo que traz uma pesquisa relevante", ou seja, que ofereça uma contribuição, que tenha importância. Essa caracterização está em consonância com um dos propósitos comunicativos desse gênero, que é o de justamente divulgar resultados de uma pesquisa (Motta-Roth; Hendges, 2010). No entanto, há um diferencial na fala de Alan: o artigo precisa trazer uma pesquisa relevante, ou seja, não se trata de qualquer pesquisa, mas de uma investigação que se destaque das que já foram desenvolvidas. Nesse caso, o artigo "atende a seus objetivos", segundo ele. O estudante acrescenta ainda que um "bom" artigo é aquele "que traz boas referências daquilo que já é consolidado na literatura", sinalizando o entendimento de que, para desenvolver pesquisas, é preciso conhecer o que já foi publicado na área sobre o objeto de estudo focalizado, bem como dar visibilidade a essa produção científica, desde que sejam "boas referências". Essa fala de Alan está aliada a uma das práticas letradas acadêmicas que regem o desenvolvimento de pesquisas, qual seja, a inserção, no texto acadêmico, de diferentes vozes de autoridades na área (Boughey, 2000), a fim de fundamentar/fortalecer a argumentação construída.

Marcos demonstra uma visão semelhante à de Alan quanto ao que considera um "bom" artigo científico:

Um artigo que tenha uma boa motivação, que tenha relevância para a comunidade técnica... E além de ter motivação, tem relevância... Tem também uma contribuição, ou seja, tem que ter alguma novidade, tem que abarcar um tema que é importante, mas, ao mesmo tempo, usar um método que de alguma forma tem que ser novo... Se o artigo cumprir com esses requisitos, ele é considerado bom (Entrevista, Marcos, 2019).

No fragmento apresentado, Marcos elenca alguns fatores que, na sua opinião, são necessários para o artigo científico ser considerado "bom": "que tenha uma relevância para a comunidade técnica", "tem também uma contribuição, ou seja, tem que ter alguma novidade, tem que abarcar um tema que é importante", "usar um método que de alguma forma tem de ser novo". Nessa fala, percebemos o uso recorrente de substantivos (relevância, contribuição, novidade) e de adjetivos (importante, novo) para sinalizar propósitos comunicativos da produção desse gênero. Todos esses propósitos 
estão relacionados a um objetivo mais amplo, já mencionado, a contribuição que o artigo precisa oferecer. Para Street (2010b), a contribuição é uma das dimensões escondidas da produção de artigos acadêmicos, que tende a não ser explicitamente ensinada aos produtores desse gênero. $\mathrm{O}$ autor destaca que essa dimensão pode se configurar de, pelo menos, três formas: contribuição para a área do conhecimento, para área de pesquisa ou para futuras pesquisas (Street, 2010b). Embora seja considerada uma dimensão escondida, os entrevistados frequentemente a sinalizaram como decisiva na produção de um "bom" artigo. Outro exemplo é a fala de Luiz:

\begin{abstract}
Ele tem que ser claro, no que ele se propõe a fazer [...] a partir de querer colocar com clareza as informações que ele quer trazer, as contribuições que ele quer fazer. Porque, não adianta tu fazer um artigo de alguma coisa que alguém já fez. E tipo tu chegar para uma pessoa e dizer que $1+1$ é 2 , tipo, beleza está certo, mas não está trazendo nenhum avanço, então, principalmente na área da gente que é tecnologia, é um negócio bem... E rápido, os avanços são muito rápidos, então você não pode perder tempo fazendo algo que alguém já fez. Vai ser inútil [...] (Entrevista, Luiz, 2019).
\end{abstract}

Nesse trecho, Luiz concebe a produção de um artigo científico como uma possibilidade de colocar as "contribuições que ele [o artigo] quer trazer". Para o estudante, o "bom" artigo é aquele que não repete algo que já foi dito, mas busca algo inovador e atual para a área, "Porque não adianta tu fazer um artigo de alguma coisa que alguém já fez", pois, "na área da gente que é tecnologia, é um negócio bem... É rápido, os avanços são muito rápidos, então você não pode perder tempo fazendo algo que alguém já fez. Vai ser inútil". Essa observação feita por Luiz reforça a dos demais participantes em relação aos propósitos da produção de artigos científicos, segundo Street (2010b) e Motta-Roth e Hendges (2010). Além disso, evidencia a relação entre o fazer científico na área de elétrica, situado no âmbito da tecnologia, cujos avanços são cada vez mais velozes, e a materialização disso na produção do artigo científico, que reflete essa forma de lidar com a produção de conhecimentos: publicar algo que sinalize avanço na área, que seja útil para a comunidade acadêmica e extracadêmica. De fato, a divulgação do conhecimento científico por meio da produção de gêneros textuais está intimamente ligada às especificidades dos modos de construir conhecimentos nas diferentes áreas, como Leitão e Pereira (2014) constataram ao analisarem resumos de artigos científicos produzidos em diversas áreas.

Considerando os trechos analisados nesta seção, percebe-se que, subjacente aos modos pelos quais Alan, Marcos e Luiz caracterizam um "bom" artigo científico em Engenharia Elétrica, está a concepção de escrita como prática social (Ivanic, 2004). Esses estudantes são unânimes em destacar o propósito comunicativo de produzir um artigo, situando-o dentro da área da qual fazem parte e apontando sempre a necessidade de o artigo oferecer uma contribuição significativa. Suas falas estão ligadas, assim, à compreensão de que a escrita, no caso de um artigo científico, acontece dentro de um contexto social e situado (área de Engenharia 
Elétrica), norteada por determinado(s) objetivo(s) que se pretende alcançar, (divulgar pesquisa relevante, inovadora, que ofereça alguma contribuição). É o cumprimento dessas metas comunicativas que permite perceber a escrita enquanto uma prática social (Ivanic, 2004). Os estudantes entendem, assim, que os artigos científicos devem ter um propósito comunicativo, trazendo implicações para a área na qual se inserem.

No entanto, a forma de conceber artigos científicos depende muito das especificidades das áreas de conhecimento, das concepções teóricometodológicas dos professores que os demandam em sala de aula e da política editorial dos periódicos nos quais são publicados, entre outros fatores. Por exemplo, enquanto esses estudantes do curso de Engenharia Elétrica destacam como propósito comunicativo do artigo científico divulgar uma pesquisa relevante para a área, graduandos do curso de Psicologia entrevistados por Silva e Castanheira (2019) são unânimes em afirmar que produziam artigo para o professor, com o objetivo de receber uma nota, configurando-se, assim, como um trabalho escolar demandado no final de muitas disciplinas do curso.

Voltando à categorização que Navarro (2019) faz sobre os gêneros científicos-acadêmicos, considerando seus objetivos sociodiscursivos (gêneros especializados e gêneros de formação), é possível dizer que as caracterizações feitas pelos estudantes de Psicologia evidenciam a perspectiva de gêneros de formação (o artigo é exigido pelo professor a fim de mediar a aprendizagem do aluno). Já as caracterizações feitas pelos estudantes de Engenharia Elétrica sugerem a perspectiva de gêneros especializados (ênfase nos propósitos comunicativos do gênero artigo científico publicado em revistas da área: permite a construção, a comunicação e a negociação de conhecimentos entre membros especializados das culturas disciplinares), conforme definidos por Navarro (2019).

\section{Artigo científico como prática sociopolítica}

Alguns participantes da pesquisa, em menor escala, ao caracterizarem um "bom" artigo científico na área de Engenharia Elétrica, deram ênfase aos significados ideológicos e identitários advindos da produção desse gênero. A seguir, a caracterização feita por Caio:

Então o que é um bom artigo? Publicar numa revista que tem Qualis boa... Bom e que tem um fator de impacto elevado. Claro, se ele obviamente está publicado num desses quesitos é porque o artigo tem relevância científica, tem novos desenvolvimentos e tem resultados promissores, porque não é só fazer o artigo. Quando você vai lá escrever a conclusão, sempre no último parágrafo você coloca... E ... Possíveis trabalhos futuros, né? Outras pessoas vão ler, né? Vão citar e aquilo que ficou em aberto outras pessoas podem fazer [...] (Entrevista, Caio, 2019).

Analisando o segmento apresentado, identificam-se alguns critérios elencados por Caio para caracterizar um "bom" artigo científico: "Publicar numa revista que tem Qualis boa... Bom e que tem um fator de impacto 
elevado". Observa-se que, mesmo ele reconhecendo que "se ele [o artigo] obviamente está publicado num desses quesitos é porque o artigo tem relevância científica, tem novos desenvolvimentos e tem resultados promissores", o destaque dado é para a publicação em revistas que tenham bom Qualis. Subjacente a esse critério está o entendimento que ele próprio explicita a seguir: "não é só fazer o artigo". Em outras palavras, para Caio, é preciso estar atento tanto ao conteúdo do artigo ("traz pesquisa relevante"), sobretudo quanto aos valores agregados ao local em que será publicado (revista com bom Qualis e com elevado fator de impacto). Ele demonstra estar ciente da influência ideológica do local de publicação na construção da sua identidade de futuro pesquisador: o que significa para sua imagem social publicar em uma revista bem avaliada pela Comissão de Aperfeiçoamento de Pessoal do Ensino Superior (Capes) e em uma revista mal avaliada? Que questões ideológicas estão por trás disso? Se publica em revistas com bom Qualis, com elevado fator de impacto, ele também recebe, por extensão, os adjetivos de bom ou excelente pesquisador, fortalecendo sua identidade acadêmica, porque, como afirma Ivanic (1997), a identidade é afetada pelas práticas sociais. Se assim o for, haverá de ser reconhecido, legitimado e aceito pelos pares, pelos "guardiões do conhecimento" (Canagarajah, 2002) que avaliam se o produtor de determinado artigo está apto ou não a publicar em dada revista. Na verdade, como afirma Canagarajah (2002), os pares não só avaliam, mas têm o poder de autorizar, ou não, a publicação, por isso são considerados os "guardiões" da publicação acadêmica.

Ainda quanto ao que se espera de um "bom" artigo científico, Caio acrescenta: "Outras pessoas vão ler, né? Vão citar e aquilo que ficou em aberto outras pessoas podem fazer". Ser citado em outro(s) artigo(s) é sinal, segundo Caio, de que o artigo é bom, pois sinaliza que aquele que cita deu crédito ao resultado da pesquisa apresentada, legitimou as conclusões obtidas, reconheceu o autor como uma autoridade na área e, portanto, pode ser referenciado na produção científica. Contemplar "vozes de autoridade", nos textos acadêmicos, no caso um artigo científico, é constitutivo da produção desses textos, de acordo em Boughey (2000). Além disso, a citação dessas vozes em tais textos envolve inevitavelmente questões de poder (Quem é citado? Qual o valor/contribuição desse(a) autor(a) na/para área?).

Semelhantemente a Caio, Luiz aponta fatores que influenciam na caracterização de um "bom" artigo científico:

Eu não vejo como artigo uma coisa que eu escrevi e mandei para professora, porque, tipo, aquilo vai morrer nela e, tipo, no futuro ninguém vai olhar e dizer, "caramba, Luiz escreveu sobre isso, eu vou citar porque me ajudou no meu trabalho", eu acho que é muito mais o intuito disso (Entrevista, Luiz, 2019).

No trecho apresentado, percebe-se o destaque que Luiz dá ao públicoalvo e ao ambiente de circulação de um artigo científico como elementos que podem, em sua opinião, legitimar, ou não, esse gênero. Para ele, os textos que são exigidos por professores de disciplinas dos cursos de graduação não são artigos, "porque, tipo, aquilo vai morrer nela [na professora]". 
Luiz não reconhece o contexto de escolarização, particularmente a sala de aula, como um lugar social situado e legitimado para produção de artigos científicos, embora é possível dizer que seja (Silva, 2019). Essa esfera social é marcada por práticas letradas acadêmicas, materializadas em gêneros, a exemplo dos formativos, cujo objetivo é justamente o de mediar o processo de aprendizagem (Navarro, 2019), como é o caso de artigos científicos demandados por professores em disciplinas (Silva, 2019).

Em outras palavras, na visão desse estudante, se o leitor do texto é um professor, então, não se constitui como artigo, porque não cumprirá com a função do gênero que, segundo ele, é a de "no futuro [...] [alguém] vai olhar e dizer, 'caramba, Luiz escreveu sobre isso, eu vou citar porque me ajudou no meu trabalho'". Subjacente está a compreensão de que o artigo precisa ter mais de um leitor (que não seja o professor) e ser lido por profissionais/pesquisadores da área que poderão reconhecer o valor da pesquisa desenvolvida. A voz do professor, enquanto leitor do artigo, parece ser desconsiderada pelo estudante, porque ela não dará visibilidade ao estudo, não permitirá sua circulação. Provavelmente, o professor vai apenas corrigi-lo e atribuir uma nota. Interessa, para Luiz, que o artigo tenha vários leitores da área que poderão valorizar o que foi apresentado no artigo e até mesmo citá-lo em seus próprios artigos, permitindo maior divulgação dos resultados alcançados.

Percebe-se que Luiz está preocupado com a repercussão social que um artigo pode ter, com a possibilidade de ser bem aceito pela comunidade científica ("caramba, Luiz escreveu sobre isso") e, inclusive, ser referenciado em alguma produção científica. Nesse sentido, suas preocupações se alinham à concepção de artigo enquanto um gênero especializado, produzido para divulgar a construção, a comunicação e a negociação de conhecimentos entre os pares de uma dada comunidade disciplinar (Navarro, 2019).

Considerando os trechos analisados nesta seção, constata-se que, subjacente aos modos pelos quais Caio e Luiz caracterizam um "bom" artigo científico em Engenharia Elétrica, está a concepção de escrita como uma prática sociopolítica (Ivanic, 2004). Em suas falas, nota-se a preocupação com os significados ideológicos que perpassam o lugar em que os artigos são publicados, os seus leitores e os pesquisadores que os citam. Além disso, percebemos a preocupação dos discentes com o modo como esses aspectos interferem na sua identidade enquanto futuros pesquisadores. Esses aspectos se coadunam com o que Ivanic (2004) defende em sua caracterização da concepção de escrita como discurso sociopolítico: a escrita, no caso a do artigo científico, é moldada por relações de poder, as quais trazem consequências sociais, bem como causam efeitos sobre outras pessoas, além de repercutirem na construção da identidade daquele que escreve (o futuro pesquisador).

Compreender a escrita dessa forma, valorizando seus significados sociais e as questões ideológicas e identitárias que a constituem como tal, está em consonância também com a abordagem de escrita denominada letramentos acadêmicos (Lea; Street, 1998). Embora os autores reconheçam o potencial dessa abordagem, seja no âmbito teórico, seja no prático, eles 
defendem que ela seja associada a outras abordagens que identificaram também em sua pesquisa sobre perspectivas de professores e alunos de instituições britânicas acerca da escrita acadêmica, quais sejam: habilidades de estudo (foco nas regras gramaticais e nas convenções da língua) e socialização acadêmica (foco na estrutura dos gêneros e em seus propósitos comunicativos).

\section{Considerações finais}

Este trabalho se propôs a identificar concepções de artigos científicos de estudantes do curso de Engenharia Elétrica de uma universidade brasileira. Para tanto, realizaram-se entrevistas semiestruturadas, nas quais esses alunos tiveram a oportunidade, dentre outros aspectos, de apresentar sua visão quanto ao que seria considerado um "bom" artigo científico em sua área, de acordo com suas experiências durante a graduação.

Com base em proposições teóricas norteadoras dos discursos sobre escrita (Ivanic, 2004), analisaram-se os modos pelos quais esses estudantes caracterizavam um "bom" artigo. Ao fazê-lo, identificaram-se duas concepções: o artigo como prática social e o artigo como prática sociopolítica. Na primeira, os estudantes enfatizaram o propósito comunicativo dos artigos científicos: espaço para divulgar pesquisas relevantes, significativas e inovadoras. Já na segunda, os graduandos enfatizaram os significados ideológicos e identitários que permeiam o local de publicação do artigo, os leitores e os autores que podem citá-los na produção científica.

A exploração de tais resultados permitiu conhecer de que forma estudantes que não são da área da linguagem concebem o artigo científico. Em suas caracterizações, os graduandos em Engenharia Elétrica não citaram aspectos microestruturais (gramática, normatização), nem mesmo textuais, como decisivos para se elaborar um "bom artigo", não obstante esses aspectos sejam predominantemente elencados em "dicas" para escrever textos acadêmicos (Silva; Carvalho, 2018). Pelo contrário, os participantes da pesquisa enfatizaram aspectos mais globais desse gênero (seu propósito comunicativo e as questões de poder e de identidade que o perpassam), demonstrando uma concepção mais ampla e crítica da escrita acadêmica, em conformidade com o que propõem Lea e Street (1998), Lillis (2001) e Street (2010b).

A análise empreendida neste artigo possibilitou, assim, fortalecer a compreensão de que a produção de gêneros acadêmicos é uma prática social e situada, perpassada por questões de autoridade, poder e identidade. Alguns estudantes conseguem percebê-la dessa forma, a exemplo dos que entrevistamos. Outros, por sua vez, ainda a consideram apenas como um trabalho escolar no qual eles, enquanto alunos-avaliados, devem escrever para os professores-avaliadores, com o objetivo de verificar o rendimento da aprendizagem (Silva, 2019). Essas possibilidades de conceber os gêneros - especializados e de formação (Navarro, 2019), respectivamente - não são excludentes, pelo contrário, complementam-se, podendo ser adotadas de acordo com as exigências e especificidades das comunidades disciplinares. 


\section{Referências}

BAKHTIN, M. Estética da criação verbal. Tradução de Paulo Bezerra. 4. ed. São Paulo: Martins Fontes, 2003.

BARDIN, F. Análise de conteúdo. São Paulo: Edições 70, 2002.

BAWARSHI, A. S.; REIFF, M. J. Gênero: história, teoria, pesquisa, ensino. São Paulo: Parábola, 2013.

BOGDAN, R. C.; BIKLEN, S. K. Investigação qualitativa em educação: uma introdução a teoria e aos métodos. Porto, Portugal: Porto Editora, 1994.

BOUGHEY, C. Multiple metaphors in a understanding of academic literacy. Teachers and Teaching: theory and practice, [S. 1.], v. 6, n. 3, p. 279-290, 2000.

CANAGARAJAH, S. A. A geopolitics of academic writing. Pittsburgh: University of Pittsburgh Press, 2002.

CARROLL, A. L. Rehearsing new roles: how college students develop as writers. Carbondale: Southern Illinios University Press, 2002.

DEVITT, A. Writing genres. Carbondale: Southern Illinois University Press, 2004.

DEVITT, A. Teaching critical genre awareness. In: BAZERMAN, C.; BONINI, A.; FIGUEIREDO, D. (Ed.). Genre in a changing world. Fort Collings: The Wac Clearinghouse, 2009. p. 337-351.

FLOWER, L.; HAYES, J. Identifying the organization of writing processes. In: GREGG, L.; STEINBERG, E. (Ed.). Cognitive processes in writing. Hillsdale: Erlbaum, 1980. p. 3-30.

FREEDMAN, A. Show and tell? The role of explicit teaching in the learning of new genres. Research in the teaching of English, [S. 1.], v. 27, n. 3, p. 222-251, Oct. 1993.

GUSTAVII, B. Como escrever e ilustrar um artigo científico. São Paulo: Parábola, 2017.

IVANIC, R. Writing and identity: the construction of identity in academic writing. Amsterdam: John Benjamins, 1997.

IVANIC, R. Discourses of writing and learning to write. Language and Education, [S. 1.], v. 18, n. 3, p. 220-245, Aug. 2004. 
LEA, M. R.; STREET, B. Student writing in higher education: an academic literacies approach. Studies in Higher Education, [S. 1.], v. 23, n. 2, p. 157-172, Jun. 1998.

LEA, M. R.; STREET, B. The 'academic literacies' model: theory and applications. Theory into Practice, [S. 1.], v. 45, n. 4, p. 368-377, 2006.

LEITÃO, P. D. V.; PEREIRA, R. C. M. Com as diferentes áreas do conhecimento concebem o fazer científico? In: PEREIRA, R. C. M. (Org.). Ateliê de textos acadêmicos: didatização e construção de saberes. João Pessoa: Ideia, 2014. p. 17-88.

LILLIS, T. M. Student writing: access, regulation, desire. Abingdon: Taylor \& Francis e-Library, 2001.

LOPES, L. P. M. (Org.) Por uma linguística aplicada indisciplinar. Campinas: Parábola, 2006.

MARCONI, M. A.; LAKATOS, E. M. Fundamentos de metodologia científica. 5. ed. São Paulo: Atlas, 2003.

MICCOLI, L. A experiência na linguística aplicada ao ensino de línguas estrangeiras: levantamento, conceituação, referências e implicações para pesquisa. Revista Brasileira de Linguística Aplicada, Belo Horizonte, v. 6, n. 2, p. 207-248, 2006.

MOREIRA, H.; CALEFFE, L. G. Metodologia da pesquisa para o professor pesquisador. 2. ed. Rio de Janeiro: Lamparina, 2008.

MOTTA-ROTH, D.; HENDGES, G. H. Produção textual na universidade. São Paulo: Parábola, 2010.

NAVARRO, F. Aportes para una didáctica de la escritura académica basada en géneros discursivos. DELTA: Documentação de Estudos em Lingüística Teórica e Aplicada, São Paulo, v. 35, n. 2, p. 1-32, 2019.

OLIVEIRA, H. A. G. O graduando em letras e a escrita: entre representações e vozes como espaço de ação discursiva. 2016. Dissertação (Mestrado em Linguagem e Ensino) - Unidade Acadêmica de Letras, Universidade Federal de Campina Grande, Campina Grande, 2016.

RODRIGUES, R. H. Os gêneros do discurso na perspectiva dialógica da linguagem: a abordagem de Bakhtin. In: MEURER, J. L.; BONINI, A.; MOTTA-ROTH, D. (Org.). Gêneros: teorias, métodos e debates. São Paulo: Parábola, 2005. p. 152-183.

SILVA, E. M. Ler e escrever na universidade: uma tese sobre a escolarização de textos acadêmicos. Revista Vozes dos Vales, [Diamantina], v. 15, n. 8, p. 1-29, 2019. 
SILVA, F. V.; CARVALHO, J. L. Q. Dicas que vão te salvar! Concepções de escrita acadêmica em blogs especializados e em outros sites de consulta. In: SILVA, F. V.; OLIVEIRA, H. A. G. A escrita no ensino superior: saberes, métodos e gêneros. São Carlos: Pedro \& João Editores, 2018. p. 141-166.

SILVA, E. M.; CASTANHEIRA, M. L. Práticas de letramento acadêmico: uma análise das condições de produção da escrita em cursos de graduação. Revista Diálogo das Letras, Pau dos Ferros, v. 8, n. 3, p. 2-21, set./dez. 2019.

STREET, B. Literacy in theory and practice. Cambridge: Cambridge University Press, 1984.

STREET, B. Os novos estudos sobre o letramento: histórico e perspectivas. In: MARINHO, M.; CARVALHO, G. (Org.). Cultura escrita e letramento. Belo Horizonte: Editora UFMG, 2010a. p. 33-53.

STREET, B. Dimensões "escondidas" na escrita de artigos acadêmicos. Perspectiva, Florianópolis, v. 28, n. 2, p. 541-567, jul./dez. 2010b.

SWALES, J. Genre analysis: English in research and academic settings. Cambridge: Cambridge University Press, 1990.

Recebido em 15 de outubro de 2019.

Aprovado em 10 de agosto de 2020. 